\title{
Investigation of Payne effect in heat protective materials containing microspheres modified by element organic modifiers.
}

\author{
Kablov VF, Novopoltseva OM, Keybal NA, Kochetkov VG* \\ Volzhsky Polytechnical Institute (Branch) VSTU, 42a Engelsa Street, Volzhsky, 404121, Russia
}

\begin{abstract}
The paper considers the impact of the introduction of alumino silicate microspheres on value of the effect Payne and physico-mechanical properties of the elastomer compositions used in the thermal protective materials. It has been shown that the use of pre-modified microspheres can increase the degree of interaction between the rubber-filler. It is found that increasing the filler-filler interaction contributes to the formation of additional spatial crosslinks exerting a reinforcing effect in the coke layer under conditions ablation erosion and breaking of the material the high velocity gas stream.
\end{abstract}

Keywords: Elastomers, Rubber fillers, Modifiers, Payne effect, Microspheres.

Accepted on August 16, 2017

\section{Introduction}

Processes of filler-filler and elastomer-filler interactions are an important characteristic for the elastomer compositions working in dynamic conditions. Typically, filler-filler interactions or the formation of spatial grid is estimated by volume of Payne effect, i.e., reduction dynamic elastic modulus at low strain and increasing dynamic elastic modulus at high deformation. The value of Payne effect correlates with the dispersion degree of the active filler agglomerates and the quantity of maximum deformation per cycle - with material viscosity at the beginning of loading, and thereby a peak load (e.g., at the time of loading rollers) $[1,2]$.

When creating a fire and thermal protection materials increase the interaction of the filler-filler is not uniquely negative. At an acceptable reduction of physical and mechanical properties increase interaction filler-filler promotes the formation of additional spatial crosslinks exerting a reinforcing effect in the coke layer under conditions ablation erosion and breaking of the material the high velocity gas stream $[3,4]$.

There were investigated the influence the introduction of alumino-silicate microspheres (MFS) on Payne effect in rubber based on ethylene-propylene caoutchouc containing 30 parts by weight filler (BS-120) and sulfuric curatives. The impact of the microspheres content on physical and mechanical characteristics of the elastomer composition and the Paine effect are presented in Table 1.

It follows from the above data, the increased content of MSF leads to increase Payne effect by 20-30\%, which indicates an increase in the filler-filler interactions in the rubber matrix. The constant value of the elastic component of the shear modulus for large deformation, demonstrates consistency in the contribution of the hydrodynamic effect module, polymer-filler interaction and "structure inside the rubber" [5].

The data in Table 1 show that the introduction of MSF allows increase conditional tensile strength by $20 \%$ to $40 \%$.

The surface of the microspheres covered with netting hydroxyl ions that are responsible for expression of the adsorption properties of alumino-silicates while flows surfactant chemical interaction [6]. The authors, i.e., Poluektova, Coll, Hajiyev and Ozherelev [7-10], taking into account the possible coordination bond of aluminum atom in the aluminum silicate, the active center is considered the aluminum atom with a coordination number 3. At interaction of macromolecules, forming carbocation with alumino-silicate, coordination number of aluminum atom becomes 4 according to the scheme (Figure 1) [11].

Thus, an increase in tensile strength conditional upon administration 1 pbw microspheres may be associated to form

Table 1. The impact of the microspheres content on Paine effect, rheological and physico-mechanical characteristics of the elastomer composition.

\begin{tabular}{|c|c|c|c|c|c|}
\hline \multirow{2}{*}{ Processing aids, index } & \multicolumn{5}{|c|}{ The content of the MSF, phr 100 wt. $h$. the rubber } \\
\hline & Control & $1 \mathrm{MSF}$ & 3 MSF & 5 MSF & $10 \mathrm{MSF}$ \\
\hline MSF & - & 1 & 3 & 5 & 10 \\
\hline \multicolumn{6}{|c|}{ Properties of rubber mixtures and elastomer compositions } \\
\hline$\Delta \mathrm{G}^{\prime}$ & 55.37 & 59.44 & 64.22 & 65.29 & 69.74 \\
\hline$f_{p} . \mathrm{M} \Pi \mathrm{a}$ & 9.1 & 13.0 & 12.1 & 10.9 & 9.2 \\
\hline w. \% & 264 & 243 & 219 & 184 & 175 \\
\hline \multicolumn{6}{|c|}{ Changing vulcanizate properties after aging in air $\left(125^{\circ} \mathrm{C}, 72 \mathrm{~h}\right)$} \\
\hline$\Delta f_{p} . \%$ & -35.1 & -32.7 & -33.5 & -36.2 & -36.9 \\
\hline$\Delta \varepsilon_{\text {отн }} \cdot \%$ & -40.5 & -39.7 & -40.2 & -41.2 & -42.0 \\
\hline
\end{tabular}

Note: $\Delta \mathrm{G}^{\prime}-$ Payne effect. $f_{p}$ - Tensile strength. $w$ - Degree of swelling in toluene. $\Delta f_{p} . \Delta \varepsilon_{\text {отн }}-$ Relative change in index equal to the ratio of the difference between its values before and after aging to the initial value 
Citation: Kablov VF, Novopoltseva OM, Keybal NA, et al. Investigation of Payne effect in heat protective materials containing microspheres modified by element organic modifiers. J Chem Tech App. 2017;1(1):1-4.

additional adsorption bonds. About the flow of such processes may indicate a reduction in the degree of swelling of the samples.

However, upon further increase microsphere content conventional tensile strength is decreased that is apparently due to a decrease of rubber homogeneity.

To improve the distribution of the microspheres and increase the degree of interaction between MSF and the polymer matrix was carried out pre-treatment of MSF phosphorus boron nitrogen containing oligomer (PEDA) (Figure 2). This makes possible forming on a MSF surface protective film, and improves the heat-shielding characteristics of the entire composition because PEDA is flame retardant. [4]. Modifier content is 3 parts by weight, which is optimal, as with a further increase it is a significant decline in physical and mechanical properties, and at lower doses are not provided with heat-shielding characteristics (Figure 2).

Further introduction of the elastomer composition organoelement modifier (modifier structural formula is shown in Figure 3) a decrease in Payne effect and increase interaction between the rubber-filler.

Table 2 shows the impact of PEDA on Payne effect, physical and mechanical properties of elastomer compositions, containing microspheres.

Increased interaction between the rubber filler depends on the mode of administration PEDA. The greatest effect has no the additive introduction, and pre-treatment of the surface of the MSF by solution PEDA or microwave treatment of a MSF and FEDA mixture (Figure 3).

Also at the microwave treatment is observed increase in the elastic component of the shear modulus at high strain amplitudes, which may be explained by the increase in the contribution to the hydrodynamic effect module, polymer-filler interaction and "structure inside the rubber" with the addition of a modifier.

This change in properties might be associated with flowing surfactant-chemical interaction between PEDA and MSF (Figure 4).

When using soft temperature exposure, there may be coordination bonds, hydrogen-aluminum, and the formation of compounds like quaternary ammonium salts.

Thus, it was found that the introduction of the microspheres in the elastomer compositions leads to increase filler-filler interactions

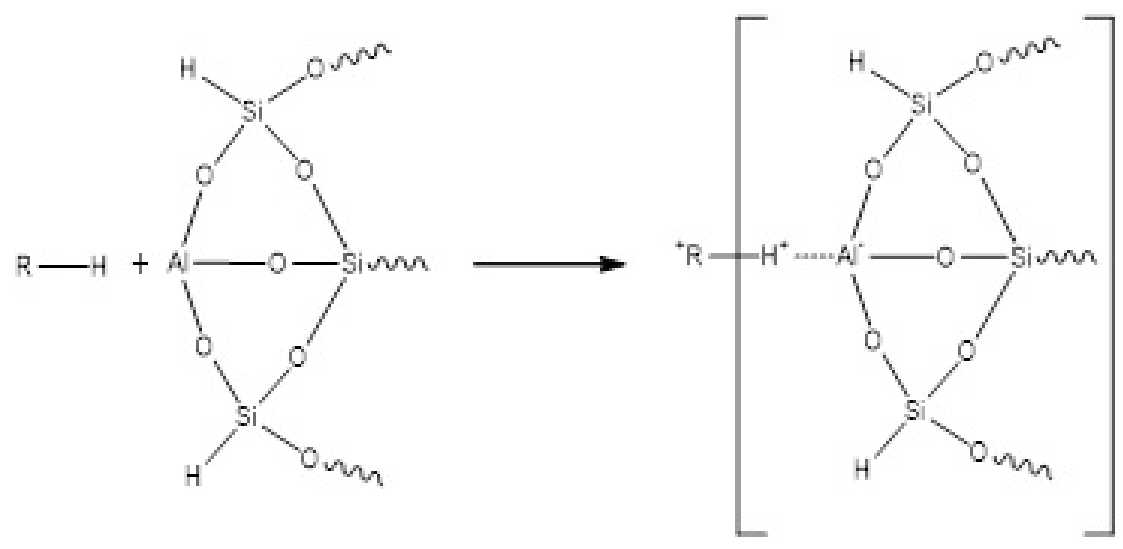

Figure 1. The proposed scheme of interaction between the MFS and elastomer matrix.

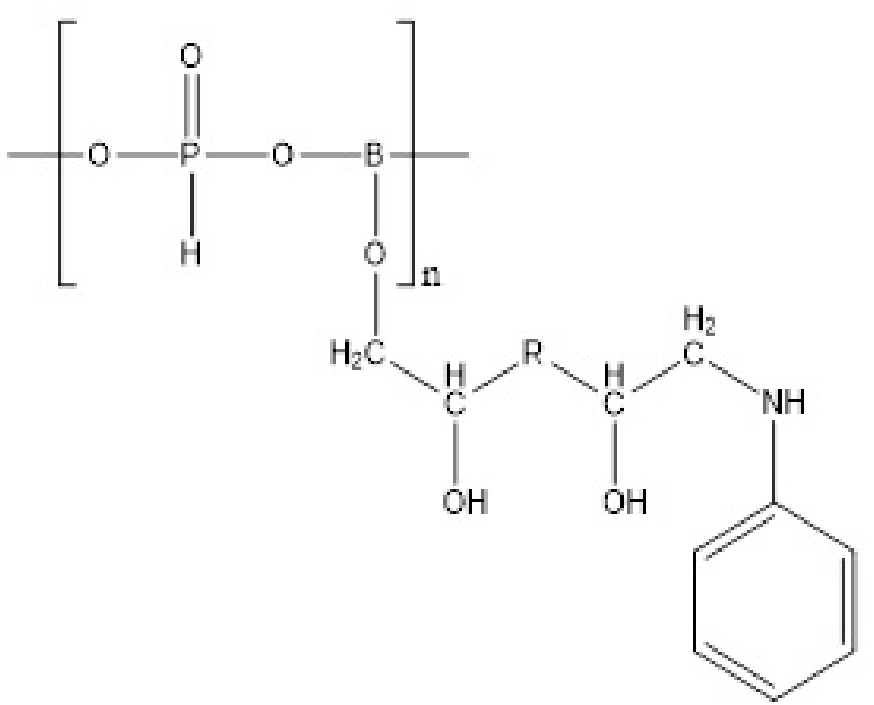

Figure 2. The structural formula is used element organic modifier PEDA. 


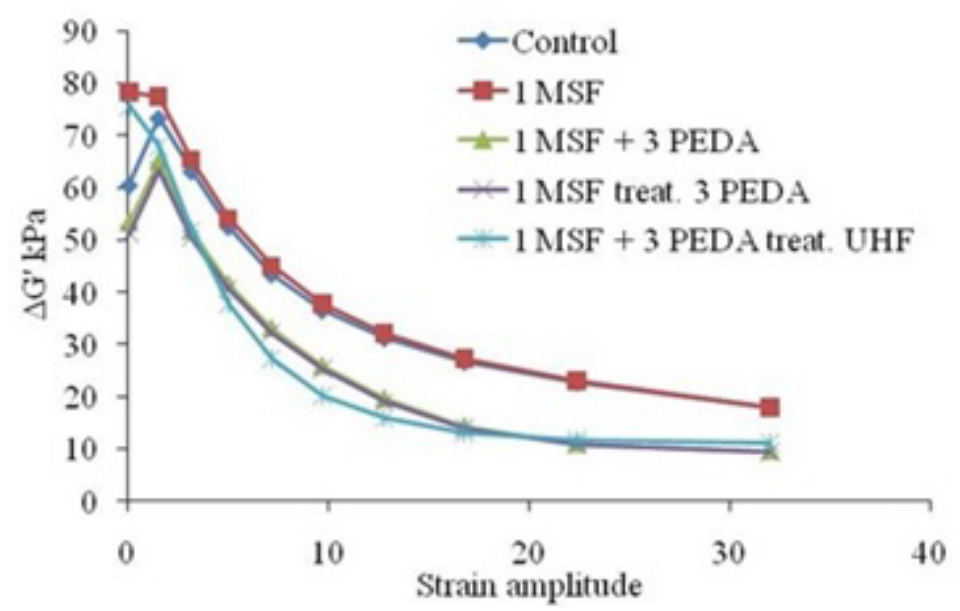

Figure 3. The dependence of the elastic component of the shear modulus $\left(\Delta G^{\prime}\right)$ of the strain amplitude.

Table 2. The impact of PEDA on Payne effect, rheological and physico-mechanical properties of elastomer compositions, containing microspheres.

\begin{tabular}{|c|c|c|c|c|c|}
\hline \multirow{2}{*}{ Processing aids, index } & \multicolumn{5}{|c|}{ The content of the ingredients, phr $100 \mathrm{wt}$. h. the rubber } \\
\hline & Control & $1 \mathrm{MSF}$ & 1 MSF + 3 PEDA & 1 MSF treat. PEDA & 1 MSF + 3PEDA treat. UHF \\
\hline MSF & - & 1 & 1 & 1 & 1 \\
\hline PEDA & - & - & 3 & 3 & 3 \\
\hline \multicolumn{6}{|c|}{ Properties of rubber mixtures and elastomer compositions } \\
\hline$\Delta \mathrm{G}^{\prime}$ & 55.37 & 59.44 & 55.47 & 53.94 & 56.81 \\
\hline$f_{p} . \mathrm{M} П \mathrm{a}$ & 9.13 & 13.97 & 10.28 & 10.57 & 11.00 \\
\hline w. \% & 264 & 243 & 228 & 215 & 234 \\
\hline \multicolumn{6}{|c|}{ Changing vulcanizate properties after aging in air $\left(125^{\circ} \mathrm{C}, 72 \mathrm{~h}\right)$} \\
\hline$\Delta f_{p} . \%$ & -35.1 & -32.7 & -30.1 & -30.3 & -29.4 \\
\hline$\Delta \varepsilon_{\text {отн }} \%$ & -40.5 & -39.7 & -38.4 & -37.9 & -38.6 \\
\hline
\end{tabular}

Note: $\Delta G^{\prime}-$ Payne effect. $f_{p}$ - Tensile strength. $w$ - Degree of swelling in toluene. $\Delta f_{p^{*}} . \Delta \varepsilon_{\text {отн. }}-$ Relative change in index equal to the ratio of the difference between its values before and after aging to the initial value.

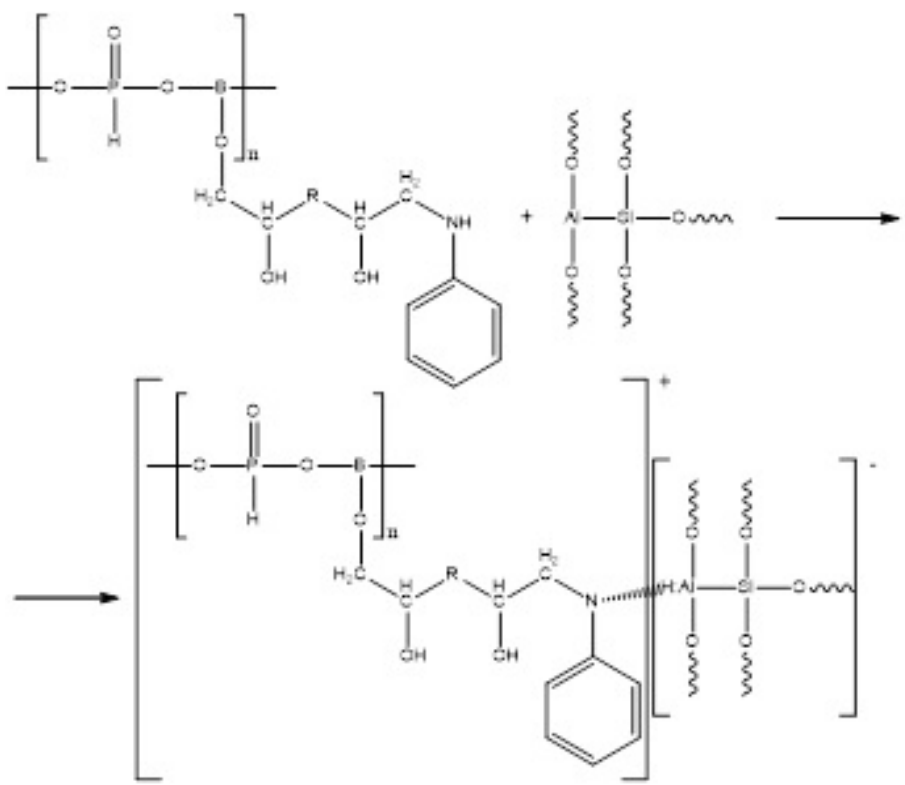

Figure 4. The proposed scheme of interaction between the MFS and PEDA.

in the rubber matrix. The constant value of the elastic component of the shear modulus for large deformation, demonstrates consistency in the contribution of the hydrodynamic effect module, polymer-filler interaction and "structure inside the rubber." Further introduction organo-element modifier a decrease Payne effect and increase interaction between the rubber-filler. Consequently, when selecting the optimal ratio of rubber-microsphere-FEDA possible the formation of additional cross-linked structures within the elastomeric matrix, exerting a reinforcing effect in the coke layer under conditions ablation erosion and breaking of the material the high velocity gas stream. 
Citation: Kablov VF, Novopoltseva OM, Keybal NA, et al. Investigation of Payne effect in heat protective materials containing microspheres modified by element organic modifiers. J Chem Tech App. 2017;1(1):1-4.

The work was supported by the initiative of the project № 10.6942.2017/CU "Development of polymer composite materials with improved fire, heat-shielding properties" performed within the base of the state task on 2017-2019 years.

\section{References}

1. Kablov VF, Keybal NA. The synthesis and the use of phosphorus, boron, nitrogen-containing oligomers for improved fire and thermal protection adhesive properties of polymeric materials. News of VSTU. 2015; 7(164):139-48.

2. Kablov VF, Novopoltseva OM, Kochetkov VG. Investigation of the effect of the modified aluminosilicate fillers for fire resistance elastomeric compositions. News of VSTU. 2015; 4(159):84-85.

3. Zaikov GE, Kalugina EV, Gumargalieva KZ. Fundamental regularities of thermal oxidation of heat-resistant heterochain polymers - Thermal Stability of Engineering Hetero-chain Thermo-resistant Polymers. Utrecht, Boston. 2004; 280.

4. Kablov VF, Novopoltseva OM, Kochetkov VG. The main ways and mechanisms to improve fire-resistance heatproof materials. News of VSTU. 2016; 4(183):46-60.

5. Kandyrin, KL Sedov AS. Application of the device RPA to assess the properties of filled rubber. Questions of practical technology manufacturing tires. 2010; 1(50):93-100.

6. Abdullayev NM. Improving the technology of adsorbents local multi-mineral clays. Dissertation for the degree of Master of the Ministry of Higher and Secondary Special Education of the Republic of Uzbekistan-Bukhara Technological Institute of Food and Light Industry, Bukhara. 2011; 84:1.

7. Poluektova EF. Bentonite clay of Ukraine, coll. 4. Kiev, Ukrainian Academy of Sciences Publishing House, Ukraine. 1960; 31:1.

8. Coll DA. The exploration and use of clay. Publishing house of Lviv University, Ukraine. 1958; 686.

9. Hajiyev RG, Negreev VF. Bentonite clay (gilabi) of Azerbaijan. Publishing house of the Academy of Sciences of Azerbaijan, Baku, Azerbaijan, SSR. 1951; 81:1.

10. Ozherelev DI, Maslyaev VS, Usikova EA. Natural mineral sorbents. Kiev, Publishing house of Ukrainian Academy of Sciences, Ukraine. 1960; 238:1.

11. Kablov VF, Novopoltseva OM, Keibal NA, et al. Elastomer thermal protection materials containing aluminosilicate microspheres. JCDNM. 2017; 9(2):1.

\section{*Correspondence to:}

Kochetkov VG

Volzhsky Polytechnical Institute (Branch) VSTU

42a Engelsa Street

Volzhsky, 404121

Russia

Tel no: 8443-25-25-92

E-mail: Geminy-I@Mail.Ru; Www.Volpi.Ru 